Психология. Журнал Высшей школы экономики,

2020. T. 17. № 4. C. 719-736. DOI: 10.17323/1813-8918-2020-4-719-736

\title{
ИННОВАТИВНОСТЬ ЛИЧНОСТИ: ИССЛЕДОВАНИЕ ПАРАМЕТРОВ ПСИХОЛОГИЧЕСКОЙ СИСТЕМЫ ДЕЯТЕЛЬНОСТИ ВУЗОВСКОЙ МОЛОДЕЖИ
}

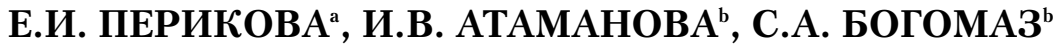

${ }^{a}$ Санкт-Петербургский государственный университет, 199034, Россия, Санкт-Петербург, Университетская наб., д. 7-9

${ }^{b}$ Национальный исследовательский Томский государственный университет, 634050, Россия, Томск, пр. Ленина, д. 36

\begin{abstract}
Резюме
Представлены результаты исследования параметров психологической системы деятельности в контексте инновативности на примере вузовской молодежи г. Санкт-Петербурга. Исследование готовности современной молодежи к инновационной деятельности представляет значительный интерес как с точки зрения личностно-профессионального становления в условиях высшего образования, так и с позиции вовлечения вузовской молодежи в инновационную деятельность в ведущих вузах страны. В качестве методического инструментария исследования использованы Опросник самоорганизации деятельности (Мандрикова, 2010), Дифференциальный тест рефлексивности (Леонтьев, Осин, 2014), Опросник ЭмИн (Люсин, 2009) и Опросник «Стили реагирования на изменения» (Базаров, Сычева, 2012). В исследовании приняли участие 244 студента второго года обучения Санкт-Петербургского государственного университета. В статье обсуждаются результаты корреляционного, факторного и регрессионного анализа. Показано, что значимыми параметрами для развития инновативных качеств современной вузовской молодежи являются наличие целей, способность к системной рефлексии, ориентация на настоящее во временно́й перспективе и межличностный эмоциональный интеллект. Фиксация на выполнении какой-либо задачи и склонность к планированию могут оказывать сдерживающий эффект на реализацию личностной готовности к инновационной деятельности. Реализующий стиль реагирования на изменения определяется выраженностью как межличностного, так и внутриличностного эмоционального интеллекта, а также характеризуется наличием целей, проявлением настойчивости в их достижении и ориентацией на настоящее. В исследовании впервые показана высокая значимость эмоционального интеллекта в качестве параметра психологической системы деятельности современной молодежи в контексте развития инновативности.
\end{abstract}

Ключевые слова: инновативность, психологическая система деятельности, целеполагание, планирование, рефлексия, эмоциональный интеллект, стили реагирования на изменения, вузовская молодежь.

Исследование выполнено при финансовой поддержке РФФИ, проект № 18-013-00781. 


\section{Введение}

Современное состояние наук о человеке характеризуется тем, что все бо́льшую популярность приобретает стратегия исследователей и специалистов учитывать социальные и психологические процессы для тщательного анализа и глубокого понимания долгосрочных эффектов экономических и политических явлений (Sirgy et al., 2006). В таком ракурсе проблема высококачественного человеческого капитала выходит на первый план и рассматривается в качестве одного из ключевых факторов инновационного прорыва страны и дальнейшего социально-экономического развития общества в целом (Аузан, 2015). В экономических науках разработаны теории самоорганизации как источника инновационной активности (Эсаулова, 2012; Barsh et al., 2008). В психологических науках исследования в данном направлении ведутся последние 15 лет в рамках изучения личностного потенциала (Атаманова и др., 2013; Богомаз, Каракулова, 2010; Богомаз, Мацута, 2010; Иванова и др., 2016; Леонтьев и др., 2007; Леонтьев, 2011, 2016; и др.).

Согласно Д.А. Леонтьеву, личностный потенциал определяется как «интегральная системная характеристика индивидуально-психологических особенностей личности, лежащая в основе способности личности исходить из устойчивых внутренних критериев и ориентиров в своей жизнедеятельности и сохранять стабильность смысловых ориентаций и эффективность деятельности на фоне давлений и изменяющихся внешних условий» (Леонтьев, 2011, c. 8). Имея сложную разветвленную структуру, личностный потенциал включает, в частности, способность к самоорганизации деятельности и рефлексии. Данные качества признаются универсальными ресурсами саморегуляции в психологической системе деятельности, поскольку позволяют реструктурировать системные связи, возникающие в процессе многочисленных взаимодействий человека с миром. Суть таких трансформаций заключается в возможности обратить в психологический ресурс то, что на первый взгляд представляется очевидным дефицитом. Д.А. Леонтьев отмечает, что «это мобилизует человека на изменение структуры и компенсаторное повышение качества саморегуляции своей жизнедеятельности» (Леонтьев, 2016, с. 24). Однако следует отметить энергозатратность процесса саморегуляции, поскольку запас энергии расходуется как на физическую активность, так и на психологическую (Baumeister et al., 1998). В.Ю. Костенко и Д.А. Леонтьев показали, что позитивные и конструктивные параметры рефлексии, в частности системная рефлексия, оказываются положительно связанными с личностным развитием и поддерживают его (Костенко, Леонтьев, 2016).

Кроме того, современные исследования показали значимость эмоционального интеллекта в качестве параметра, который необходимо учитывать в контексте личностно-профессионального развития. Согласно полученным исследователями результатам, он связан с вербальным и невербальным интеллектом, памятью, функциями управления поведением (executive functions) (Mayer, Salovey, 2001; Schneider et al., 2016), креативностью (Averill, 2000; Ivcevic et al., 2007), успешностью человека в социуме и его менеджерскими 
качествами (Caruso, Salovey, 2004; Stein, Book, 2011), личностной готовностью к деятельности (Перикова и др., 2020). Отмеченные психологические характеристики присутствуют и в структуре психологической системы деятельности (Шадриков, 2013). С.А. Богомаз и В.В. Мацута продемонстрировали, что коммуникативная компетентность является одним из ключевых личностных качеств для обеспечения вовлеченности вузовской молодежи в инновационную деятельность (Богомаз, Мацута, 2014). При этом «некоммуникативность» была отнесена к психологическим дефицитам, затрудняющим овладение социально-личностными компетенциями. Рефлексия и эмоциональный интеллект рассматриваются исследователями в качестве ресурса инновационной активности в профессиональной деятельности (Эльмурзаева, 2011). Т.О. Гордеева с коллегами в своих работах показали, что способность индивида управлять своим поведением и эмоциями и прерывать действия, обусловленные нежелательными импульсами и эмоциями, является важным личностномотивационным ресурсом, характеризующим зрелую личность (Гордеева и др., 2016).

Изучение отношения к инновациям в последние десятилетия привлекало большое внимание специалистов. Можно выделить три направления такого рода исследований: 1) создание и апробирование исследовательского инструментария для изучения инноваций (например: Базаров, Сычева, 2012; Baker, Mehmood, 2015; Gerometta et al., 2005; Glor, 2015); 2) разработка концепций и определений, связанных с инновациями (например: Fujisawa et al., 2015; Kuehlwein, Rosen, 1993); 3) прикладные исследования отношения к инновациям (Богомаз, Непомнящая, 2007; Atamanova et al., 2015; Bogomaz et al., 2015; Sheldon et al., 2017). Современные исследования сосредоточены на изучении параметров инновативности личности, которые определяют готовность к изменениям и модернизации жизни личности и жизни страны в целом.

В этом смысле исследование готовности молодежи к инновационной деятельности представляет значительный интерес, поскольку данная возрастная когорта рассматривается специалистами различных научных отраслей и руководством страны в контексте прорывного социально-экономического развития государства и общества (Аузан, 2015; Атаманова и др., 2018). Особое внимание привлекают в этом смысле исследования вузовской молодежи, обучающейся в ведущих высших учебных заведениях России.

Инновационная деятельность студенческой молодежи обусловливает формирование определенного типа личности, обладающего инновационностью (инновационным мышлением) как особой способностью к восприятию, созданию и внедрению новых и оригинальных идей (Артемьева и др., 2018).

Цель нашего исследования заключалась в выявлении специфики параметров психологической системы деятельности в контексте инновативности на примере вузовской молодежи г. Санкт-Петербурга. В исследовании приняли участие студенты естественнонаучных направлений Санкт-Петербургского государственного университета (СПбГУ). Обладая высоким статусом среди российских и иностранных вузов, СПбГУ входит в группу 301-400 шанхайского рейтинга Academic Ranking of World Universities (ARWU). Кроме того, 
университет входит в топ-225 лучших университетов мира рейтинга Quacquarelli Symonds. Большое количество исследований университета связано с биологическими и психологическими науками, на его базе действуют 10 лабораторий в рамках тематики наук о жизни и биотехнологий, что предопределило фокус исследовательского интереса.

\section{Методика исследования}

\section{Участники}

В исследовании приняли участие студенты (Санкт-Петербургский государственный университет) второго года обучения естественнонаучных направлений подготовки (средний возраст составил $19.63 \pm 1.21$ года; девушки $78.5 \%$, юноши - 21.5\%; общее количество участников исследования - 244 человека). В соответствии с разработанной процедурой исследования участникам было предложено заполнить бумажные версии используемых в исследовании опросников. Сбор данных происходил зимой-весной 2018 г. в условиях учебных аудиторий. Участие студентов в исследовании осуществлялось на добровольной основе; какое-либо вознаграждение не было предусмотрено.

\section{Методики}

Для выявления степени выраженности параметров психологической системы деятельности были использованы следующие методики:

1) Опросник самоорганизации деятельности (СД) Е.Ю. Мандриковой (2010) применялся для оценки способности к тактическому планированию и стратегическому целеполаганию. Данный опросник включает шесть шкал («Планомерность», «Целеустремленность», «Настойчивость», «Фиксация», «Самоорганизация», «Ориентация на настоящее») и один индекс «Суммарный показатель ОСД»;

2) Опросник «Дифференциальный тест рефлексивности» (ДТР), разработанный Д.А. Леонтьевым и Е.Н. Осиным (2014) и позволяющий характеризовать рефлексивные процессы человека. Для реализации задач данного исследования в анализе использовалась шкала «Системная рефлексия»;

3) Опросник ЭмИн Д.В. Люсина (2009) использовался для оценки способности участников исследования распознавать свои собственные эмоции и эмоции других людей, понимать их и управлять ими. Данный опросник содержит четыре основные шкалы («Понимание эмоций», «Управление эмоциями», «Внутриличностный эмоциональный интеллект» и «Межличностный эмоциональный интеллект») и пять субшкал («Понимание своих эмоций», «Управление своими эмоциями», «Контроль экспрессии», «Понимание чужих эмоций» и «Управление чужими эмоциями»). При обработке сырых данных также рассчитывается «Суммарный показатель ЭмИн»;

4) Опросник «Стили реагирования на изменения», разработанный Т.Ю. Базаровым и М.П. Сычевой (2012), применялся для оценки инновационных 
диспозиций личности. Опросник позволяет выделить четыре стиля реагирования на изменения («Инновационный», «Реализующий», «Консервативный» и «Реактивный»), которые трактуются его авторами с точки зрения предпочтения «определенных способов взаимодействия человека с ситуацией изменения, выражающиеся в эмоциональных, когнитивных и поведенческих реакциях» (Базаров, Сычева, 2012, с. 12). В одном из исследований в рамках реализуемого гранта нами было показано, что стили реагирования на изменения могут быть включены в число параметров, характеризующих психологическую систему деятельности (Перикова и др., 2020).

\section{Статистическая обработка}

Для статистической обработки собранных эмпирических данных применялось лицензионное программное обеспечение, реализованное пакетом статистических программ Statistica 10.0. Были использованы следующие процедуры: 1) описательная статистика (для оценки качества выборки мы анализировали среднее, стандартное отклонение, асимметрию и эксцесс); 2) t-тест Стьюдента для независимых выборок применялся для выявления статистически достоверных различий по исследуемым показателям; 3) корреляционный анализ (был использован коэффициент корреляции Пирсона) применялся для выявления взаимосвязей между исследуемыми показателями; 4) факторный анализ был реализован методом главных компонент с «Varimax»-вращением факторов; 5) применялся прямой пошаговый регрессионный анализ для оценки прогностической способности исследуемых показателей. Достоверность различий учитывалась при уровне значимости $p<0.05$.

\section{Результаты исследования}

В соответствии с описанной выше процедурой статистического анализа были вычислены описательные статистики исследуемых показателей, которые позволили оценить качество исследуемой выборки для отбора соответствующих критериев в ходе проведения дальнейшего анализа. Таблица 1 содержит описательные статистики (M - среднее, SD - стандартное отклонение, асимметрия и эксцесс) тех шкал, которые были нам необходимы для детального исследования в качестве параметров психологической системы деятельности.

В таблице 1 приведены описательные статистики 1) шести параметров самоорганизации деятельности («Планомерность», «Целеустремленность», «Настойчивость», «Фиксация», «Самоорганизация», «Ориентация на настоящее») и одного суммарного индекса «Суммарный показатель ОСД»; 2) одного показателя ДТР «Системная рефлексия»; 3) двух параметров, характеризующих эмоциональный интеллект («Межличностный эмоциональный интеллект» и «Внутриличностный эмоциональный интеллект»); 4) четырех стилей реагирования на изменения («Инновационный», «Реализующий», «Консервативный» и «Реактивный»). 
Таблица 1

Описательные статистики параметров психологической системы деятельности (в баллах) на примере вузовской молодежи г. Санкт-Петербург $(\mathrm{N}=244)$

\begin{tabular}{|l|c|c|c|c|}
\hline \multicolumn{1}{|c|}{ Исследуемые параметры } & M & SD & Асимметрия & Эксцесс \\
\hline СД: Планомерность & 17.8 & 5.43 & -0.26 & -0.57 \\
\hline СД: Целеустремленность & 30.5 & 6.86 & -0.58 & 0.09 \\
\hline СД: Настойчивость & 18.7 & 6.69 & 0.26 & -0.67 \\
\hline СД: Фиксация & 18.8 & 5.10 & 0.12 & -0.40 \\
\hline СД: Самоорганизация & 10.0 & 3.99 & 0.19 & -0.57 \\
\hline СД: Ориентация на настоящее & 7.9 & 3.08 & 0.23 & -0.43 \\
\hline СД: Суммарный показатель ОСд & 103.5 & 17.17 & 0.16 & 4.61 \\
\hline ДТР: Системная рефлексия & 40.0 & 5.50 & -1.20 & 3.25 \\
\hline $\begin{array}{l}\text { ЭмИн: Межличностный эмоциональный } \\
\text { интеллект }\end{array}$ & 44.8 & 11.07 & -0.43 & 0.58 \\
\hline $\begin{array}{l}\text { ЭмИн: Внутриличностный эмоциональный } \\
\text { интеллект }\end{array}$ & 38.0 & 9.47 & 0.05 & -0.28 \\
\hline Стили: Консервативный & 19.9 & 5.35 & 0.10 & 0.09 \\
\hline Стили: Инновационный & 19.3 & 5.27 & -0.26 & 0.04 \\
\hline Стили: Реактивный & 18.2 & 5.40 & 0.13 & -0.18 \\
\hline Стили: Реализующий & 19.3 & 5.07 & -0.17 & -0.24 \\
\hline
\end{tabular}

В целом, группа респондентов обнаружила гомогенность по возрасту. Т-тест Стьюдента для независимых выборок позволил выявить статистически значимые различия между юношами (43.6 \pm 8.9 балла) и девушками (39.4 \pm 9.1 балла) только по одной из субшкал Опросника ЭмИн: «правление эмоциями» $(t(244)=-2.962 ; p=0.003)$. Данный показатель не является критическим для исследования инновативности и психологической системы деятельности, поэтому в дальнейшем анализ проводился на общей выборке с учетом обнаруженных различий.

Далее, согласно целям исследования, был реализован факторный анализ $(\mathrm{N}=244)$ с использованием критерия Р. Кеттелла «каменистая осыпь». В ходе проведения факторного анализа было задействовано 13 переменных. В результате было выделено 5 факторов, описавших 67.0\% дисперсии исходной корреляционной матрицы. Критерий значимости исследуемых параметров определялся факторной нагрузкой показателя, превышающей 0.40 .

Фактор 1, будучи самым значимым фактором по результатам проведенного анализа, зафиксировал комплекс четырех стилей реагирования на изменения. В данный фактор вошли «Инновационный» (0.893), «Консервативный» $(-0.879)$, «Реактивный» $(-0.813)$ и «Реализующий» $(0.791)$ стили (в скобках здесь и далее указана факторная нагрузка исследуемых показателей). Можно 
Таблица 2

Результаты факторного анализа параметров психологической системы деятельности вузовской молодежи Санкт-Петербурга в контексте инновативности

\begin{tabular}{|l|c|c|c|c|c|}
\hline \multicolumn{1}{|c|}{ Исследуемые параметры } & Фактор 1 & Фактор 2 & Фактор 3 & Фактор 4 & Фактор 5 \\
\hline Стили: Консервативный & $\mathbf{- 0 . 8 7 9}$ & -0.119 & 0.132 & -0.016 & -0.224 \\
\hline Стили: Инновационный & $\mathbf{0 . 8 9 3}$ & 0.121 & -0.142 & 0.004 & 0.192 \\
\hline Стили: Реактивный & $\mathbf{- 0 . 8 1 3}$ & -0.163 & -0.164 & 0.006 & 0.328 \\
\hline Стили: Реализующий & $\mathbf{0 . 7 9 1}$ & 0.205 & 0.156 & 0.008 & -0.331 \\
\hline СД: Планомерность & -0.060 & 0.104 & 0.378 & $-\mathbf{0 . 7 0 5}$ & -0.106 \\
\hline СД: Целеустремленность & 0.299 & 0.191 & $\mathbf{0 . 6 6 0}$ & -0.178 & -0.123 \\
\hline СД: Настойчивость & 0.011 & 0.010 & -0.050 & 0.022 & $-\mathbf{0 . 9 0 0}$ \\
\hline СД: Фиксация & -0.237 & -0.086 & $\mathbf{0 . 7 6 8}$ & 0.010 & 0.130 \\
\hline СД: Самоорганизация & 0.008 & -0.015 & -0.066 & $-\mathbf{0 . 8 4 1}$ & 0.092 \\
\hline СД: Ориентация на настоящее & 0.396 & $\mathbf{- 0 . 4 1 4}$ & 0.017 & -0.038 & -0.063 \\
\hline ДТР: Системная рефлексия & 0.155 & $\mathbf{0 . 5 5 6}$ & -0.184 & -0.332 & 0.018 \\
\hline $\begin{array}{l}\text { ЭмИн: Межличностный } \\
\text { эмоциональный интеллект }\end{array}$ & 0.300 & $\mathbf{0 . 5 4 1}$ & 0.312 & -0.040 & 0.053 \\
\hline $\begin{array}{l}\text { ЭмИн: Внутриличностный } \\
\text { эмоциональный интеллект }\end{array}$ & 0.153 & $\mathbf{0 . 7 4 3}$ & 0.067 & 0.061 & -0.112 \\
\hline Собственные значения & 3.300 & 1.478 & 1.400 & 1.353 & 1.185 \\
\hline Процент объясняемой дисперсии & 25.4 & 11.4 & 10.8 & 10.4 & 9.1 \\
\hline
\end{tabular}

говорить о том, что стили реагирования на изменения выступают ведущим фактором с точки зрения личностной готовности вузовской молодежи к изменениям при первостепенном вкладе инновационного стиля.

В Факторе 2 соединились один из показателей Опросника самоорганизации деятельности («Ориентация на настоящее» $(-0.414))$, шкалу ДТР «Системная рефлексия» (0.556) и две основные шкалы Опросника ЭмИн («Межличностный эмоциональный интеллект» (0.541) и «Внутриличностный эмоциональный интеллект» (0.743)). Анализ собранных в данный фактор параметров позволяет рассматривать их комбинацию с позиции стремления респондентов к целостному восприятию и комплексной оценке возникающих ситуаций взаимодействия с миром и людьми с учетом временно́й перспективы прошлого и будущего.

Фактор 3 связал два параметра Опросника самоорганизации деятельности: «Фиксация» (0.768) и «Целеустремленность» (0.660). По нашему мнению, он 
отражает характеристику упорства в достижении результата любыми возможными способами.

В Факторе 4 с отрицательным знаком собрались две шкалы Опросника самоорганизации деятельности «Самоорганизация» $(-0.841)$ и «Планомерность» $(-0.705)$. Данный фактор, вероятно, отражает ситуативность действий и выборов молодых людей, некоторую бессистемность и непоследовательность в организации своей деятельности.

Фактор 5 включил шкалу «Настойчивость» $(-0.900)$, что можно трактовать как отсутствие волевых усилий молодых людей к достижению целей.

Проведенный корреляционный анализ выявил ряд статистически значимых взаимосвязей между исследуемыми параметрами, характеризующими психологическую систему деятельности вузовской молодежи в контексте инновативности. Здесь и далее представлены корреляционные связи с уровнем значимости $p=0.000$. В частности, консервативный стиль обнаружил отрицательные связи с одной из субшкал Опросника ЭмИн («Управление своими эмоциями»: $r=-0.280)$, одной из основных шкал («Межличностный эмоциональный интеллект»: $r=-0.271)$ и индексом «Суммарный показатель ЭмИн» $(r=-0.273)$. Также была выявлена положительная взаимосвязь с параметром самоорганизации деятельности «Фиксация» $(r=0.239)$.

В противовес предыдущему стилю, инновационный стиль отрицательно связан с параметром «Фиксация» $(r=-0.254)$ и положительно с параметрами «Управление своими эмоциями» $(r=0.268)$, «Межличностный эмоциональный интеллект» $(r=0.262)$, «Суммарный показатель ЭмИн» $(r=0.275)$.

Реактивный стиль обнаружил отрицательные связи с параметрами «Целеустремленность» $(r=-0.348)$ и рядом параметров, характеризующих эмоциональный интеллект: субшкалы «Управление чужими эмоциями» $(r=-0.258)$ и «Управление своими эмоциями» $(r=-0.352)$; основные шкалы «Внутриличностный эмоциональный интеллект» $(r=-0.268)$, «Межличностный эмоциональный интеллект» $(r=-0.306)$, «Понимание эмоций» $(r=-0.269)$ и «Управление эмоциями» $(r=-0.375)$, а также «Суммарный показатель ЭмИн» $(r=-0.318)$.

Реализующий стиль демонстрирует положительные взаимосвязи с таким параметром самоорганизации деятельности, как «Целеустремленность» $(r=0.321)$, субшкалами Опросника ЭмИн («Управление чужими эмоциями» $(r=0.251)$ и «Управление своими эмоциями» $(r=0.345))$, основными шкалами Опросника ЭмИн («Внутриличностный эмоциональный интеллект» $(r=0.300)$, «Межличностный эмоциональный интеллект» $(r=0.295)$, «Понимание эмоций» $(r=0.258)$ и «Управление эмоциями» $(r=0.397))$, а также индексом «Суммарный показатель ЭмИн» $(r=0.334)$.

С целью определения прогностического потенциала параметров психологической системы деятельности в оценке инновативных свойств личности нами был реализован прямой пошаговый регрессионный анализ $(\mathrm{N}=244)$. В качестве зависимой переменной выступил параметр «Инновационный стиль». Независимые переменные, которые использовались для регрессионного анализа, включали параметры самоорганизации деятельности, системную 
рефлексию и ряд показателей эмоционального интеллекта. Полученная модель обнаружила значимость $F(7,236)=10.3 ; p<0.0001$ и объяснила $21.1 \%$ дисперсии (скорректированный $R^{2}$ ).

Было выявлено, что предикторами исследуемого показателя «Инновационный стиль» с позитивными значениями являются параметр эмоционального интеллекта «Межличностный эмоциональный интеллект» $(\beta=0.202$; $p=0.001)$ и личностные свойства: «Целеустремленность» $(\beta=0.233 ; p=0.000)$, «Ориентация на настоящее» $(\beta=0.133 ; p=0.025)$ и «Системная рефлексия» $(\beta=0.134 ; p=0.024)$. С негативными значениями в регрессионную модель вошли «Фиксация» $(\beta=-0.281 ; p=0.000)$ и «Планомерность» $(\beta=-0.145$; $p=0.020)$ (формула 1).

$$
A=11.6+0.202 B-0.281 C+0.233 D+0.133 E-0.145 F+0.134 G,
$$

где $\mathrm{A}$ - «Инновационный стиль», В - «Межличностный эмоциональный интеллект», C - «Фиксация», D - «Целеустремленность», E - «Ориентация на настоящее», $\mathrm{F}$ - «Планомерность», $\mathrm{G}-\ll$ Системная рефлексия».

Была реализована еще одна процедура прямого пошагового регрессионного анализа. В качестве зависимой переменной в данном случае выступил показатель «Реализующий стиль» при аналогичном предыдущему анализу наборе независимых переменных. Число наблюдений - 244. Модель для анализа является значимой $F(7.236)=11.5 ; p<0.0001$ и объясняет $23.2 \%$ дисперсии.

Оказалось, что параметр «Реализующий стиль» с позитивными значениями зависит от следующих параметров: «Целеустремленность» $(\beta=0.251 ; \mathrm{p}=0.0001)$, «Внутриличностный эмоциональный интеллект» $(\beta=0.169 ; p=0.006)$, «Ориентация на настоящее» $(\beta=0.138 ; p=0.015)$, «Настойчивость» $(\beta=0.139$; $p=0.014)$ и «Межличностный эмоциональный интеллект» $(\beta=0.140 ; p=0.025)$. Негативно значимым является личностное свойство «Фиксация» $(\beta=-0.123$; $p=0.039)$.

$$
A=1.58+0.251 B+0.169 C+0.138 D+0.139 E+0.140 F-0.123 G
$$

где А - «Реализующий стиль», В - «Целеустремленность», С - «Внутриличностный эмоциональный интеллект», D - «Ориентация на настоящее», E «Настойчивость», F - «Межличностный эмоциональный интеллект», G «Фиксация».

\section{Обсуждение результатов исследования}

Анализ полученных результатов показывает, что ведущим фактором готовности вузовской молодежи к инновационной деятельности (на примере студентов Санкт-Петербургского государственного университета) оказались параметры, характеризующие стили реагирования на изменения. Аналогичный результат на студенческой выборке был получен и в работе И.В. Атамановой и С.А. Богомаза (2018). Вторым по значимости фактором выступает стремление вузовской молодежи к целостному восприятию и комплексной оценке возникающих ситуаций взаимодействия с миром и людьми, третьим - упорство в достижении поставленных целей. Четвертый и пятый факторы свидетельствуют об отсутствии системы в организации молодежью своей деятельности и 
настойчивости в достижении целей. С одной стороны, складывается в некотором смысле противоречивая картина личностных свойств и устремлений студенческой молодежи. С другой стороны, этому может быть найдено вполне логичное объяснение. Мы полагаем, что в первую очередь такое положение дел связано с ситуативностью. Молодым людям данного возраста свойственна высокая степень гибкости в выборе своих предпочтений и поведении. Это студенты, которые только два года назад переехали в большой город для учебы в университете, они делают свои первые профессиональные пробы в различных направлениях от психогенетики до политической психологии, от иммунологии до высшей нервной деятельности. В контексте личностно-профессионального становления у этих молодых людей только начинают формироваться необходимые личностные свойства, в том числе инновативные.

Обнаруженные корреляционные связи между параметрами психологической системы деятельности и стилями реагирования на изменения указывают на существенную роль эмоционального интеллекта в понимании факторов, способствующих или препятствующих вовлечению вузовской молодежи в деятельность, в том числе и инновационную. Так, для реактивного стиля реагирования на изменения характерно наличие целого ряда отрицательных статистически значимых взаимосвязей с параметрами эмоционального интеллекта как с точки зрения понимания и управления своими эмоциями, так и в отношении эмоций других. Реализующий стиль реагирования на изменения можно описать через наличие положительной статистически значимой корреляции как с внутриличностным, так и межличностным эмоциональным интеллектом. Кроме того, параметры, отвечающие за управление своими эмоциями и эмоциями других людей, также имеют значение. Инновационный стиль реагирования на изменения определяется, прежде всего, способностью вузовской молодежи управлять своими эмоциями и развитым межличностным эмоциональным интеллектом. Для консервативного стиля наблюдается обратная картина.

Результаты регрессионного анализа показывают, что инновационный стиль реагирования на изменения с позиции готовности к инновационной деятельности зависит от степени выраженности способности молодых людей к распознаванию, пониманию и управлению в отношении эмоций других людей. Наличие целей, ориентация на настоящее во временно́й перспективе и способность к системной рефлексии оказываются значимыми параметрами с точки зрения реализации своей готовности к инновационной деятельности. При этом выраженное стремление к планированию и фиксации на решаемой задаче может выступать ограничителем при реализации инновационной активности в силу характера такого рода деятельности, требующей творческого начала, гибкости и открытости новому опыту. Можно говорить в таком случае, что инновативность зависит от наличия целей у молодых людей и стремления к их достижению, самодистанцирования в оценке ситуации и при этом ориентации на настоящее.

Межличностный эмоциональный интеллект отражает способность молодых людей к социальной восприимчивости. Данное качество дает возможность распознавать и понимать эмоции других, включая управление этими 
эмоциями. Оно крайне ценно в командной работе, поскольку обеспечивает настрой на совместную деятельность и регулирование эмоционального фона в команде. Важно, что именно это свойство оказалось значимым для развития инновативности с точки зрения умения ощущать изменения и эмоционально вовлекать в них других людей. Полученные результаты отличают данное исследование от ранее проведенных (Богомаз и др., 2018; Иванова и др., 2018; Gorchakova et al., 2016), поскольку обнаружены значимые связи между инновативностью и эмоциональным интеллектом современной молодежи.

В наших исследованиях уже было показано ограничивающее влияние фиксации на определенной задаче по реализации готовности личности к деятельности (Левицкая, Богомаз, 1999). В контексте реализации готовности современной вузовской молодежи к инновационной деятельности крайне важно создавать в образовательном процессе условия для развития способности молодых людей быстро реагировать на происходящие изменения.

Довольно неожиданной оказалась выявленная отрицательная взаимосвязь инновативности с таким параметром психологической системы деятельности, как «Планомерность». Роль планомерности как потребности в постоянном осознанном планировании деятельности не полностью изучена, возможно, она оказывает сдерживающее влияние на развитие инновационной экономики. Отметим, что в работе И.В. Атамановой и С.А. Богомаза (2018) с помощью факторного анализа было выявлено, что планирование как параметр самоорганизации деятельности тесно связано со степенью приверженности молодежи традиционным ценностям.

Реализующий стиль реагирования на изменения зависит от двух ключевых параметров, характеризующих эмоциональный интеллект («Внутриличностный эмоциональный интеллект» и «Межличностный эмоциональный интеллект»), и ряда параметров самоорганизации деятельности («Ориентация на настоящее», «Целеустремленность» и «Настойчивость»). В отличие от инновационного стиля реагирования на изменения для реализующего стиля важно понимание эмоциональной составляющей как своей собственной, так и других людей, чтобы действовать в соответствии с поставленными целями, проявляя настойчивость в движении в выбранном направлении. При этом реализующий стиль, как и инновационный, ограничивается в своем проявлении склонностью молодых людей фиксироваться на выполнении конкретной задачи.

Выявлена связь настойчивости в достижении целей с инновационным и реализующим стилями реагирования на изменения. «Реализаторам», которые поддерживают и принимают изменения, важно проявление настойчивости для претворения инновационных идей в реальность. В этом проявляется бо́льшая степень сдержанности в отношении нововведений, чем у «инноваторов», у которых стиль реагирования на изменения не зависит от уровня их настойчивости в достижении целей. «Инноваторы», вероятно, более гибки в реализации своей деятельности, что нашло проявление и в отрицательной взаимосвязи между планомерностью и инновативностью. 


\section{Заключение}

Проведенный комплексный анализ позволил выявить специфику параметров психологической системы деятельности личности в контексте инновативности на примере студенческой молодежи Санкт-Петербурга. Было показано, что ведущим фактором является инновационный стиль реагирования на изменения. Значимыми параметрами для развития инновативности оказались межличностный эмоциональный интеллект, параметры самоорганизации деятельности и рефлексивность. Для развития реализующего стиля оказались значимыми способность к пониманию своих эмоций и управление ими, развитый межличностный эмоциональный интеллект и параметры самоорганизации деятельности.

Установлено наличие отрицательных взаимосвязей между инновативностью и планомерностью, а также отсутствие какой-либо связи с настойчивостью в достижении поставленных целей. Ориентация на настоящее и наличие целей являются важным личностным ресурсом для развития инновативности. Инновативно-ориентированные молодые люди обладают высоким личностным потенциалом за счет самоорганизации, рефлексии, способности к управлению своими эмоциями и межличностного интеллекта. Исследование показало, что консервативный стиль реагирования на изменения может быть обусловлен отсутствием гибкости в реализации собственной деятельности.

В данном исследовании впервые показана высокая значимость эмоционального интеллекта в качестве параметра психологической системы деятельности для развития инновативности современной молодежи в контексте их личностно-профессионального становления. Задача следующего этапа исследования - провести сравнительный анализ параметров психологической системы деятельности вузовской молодежи на примере городов Санкт-Петербурга и Томска - признанных образовательных и научных центров страны.

\section{Литература}

Артемьева, В. А., Веселова, Е. К., Дворецкая, М. Я., Коржова, Е. Ю. (2018). Социальная ответственность и инновационность личности студентов с опытом и без опыта работы по специальности. Вестник Новосибирского государственного педагогического университета, 8(5), 7390. doi:10.15293/2226-3365.1805.05

Атаманова, И. В., Богомаз, С. А. (2018). Инновативность современной молодежи и культурные факторы социально-экономического развития. В кн. Т. А. Нестик, Ю. В. Ковалева (ред.), Социальная и экономическая психология: Состояние и перспективы исследований (ч. 1, с. 281288). М.: Изд-во «Институт психологии РАН».

Атаманова, И. В., Козлова, Н. В., Богомаз, С. А., Залевский, В. Г., Неяскина, Ю. Ю. (2018). Специфика личностно-средового взаимодействия на примере студенческой молодежи трех российских городов. Вестник Томского государственного университета. Философия. Социология. Политология, 41, 90-105. doi:10.17223/1998863X/41/11 
Атаманова, И. В., Стариченко, О. Н., Богомаз, С. А. (2013). Психологические особенности магистрантов и аспирантов, обучающихся в вузах с ориентацией на классическое и инженерное образование. Вестник Томского государственного университета, 367, 128-135.

Аузан, А. А. (2015). О возможности перехода к экономической стратегии, основанной на специфике человеческого капитала в России. Журнал Новой экономической ассоциащии, 2(26), 243-248.

Базаров, Т. Ю., Сычева, М. П. (2012). Создание и апробация опросника «Стили реагирования на изменения». Психологические исследования, 5(25). Режим доступа: http://psystudy.ru

Богомаз, С. А., Каракулова, О. В. (2010). Личностный и коммуникативный потенциал инновационно- и предпринимательски-ориентированных субъектов. Сибирский психологический журнал, 37, 48-51.

Богомаз, С. А., Клочко, В. Е., Краснорядцева, О. М., Подойницина, М. А. (2018). Стратегии самоосуществления у студенческой молодежи. Вопросы психологии, 1, 49-58.

Богомаз, С. А., Мацута, В. В. (2010). Оценка личностного потенциала и выявление основных типов ориентации на профессиональную деятельность у современной вузовской молодежи. Психология обучения, 12, 77-88.

Богомаз, С. А., Мацута, В. В. (2014). Ценностные ориентации участников программы У.М.Н.И.К. и мотивация к инновационной деятельности. В кн. С. А. Богомаз, О. М. Краснорядцева (ред.), Интеллектуальный потенциал и инновационная активность вузовской молодежи (с. 100-110). Томск: Издательский дом Томского государственного университета.

Богомаз, С. А., Непомнящая, В. А. (2007). К проблеме поиска психологических оснований развития инновативной компоненты личности в юности и молодости. Сибирский психологический журнал, 25, 78-82.

Гордеева, Т. О., Осин, Е. Н., Сучков, Д. Д., Иванова, Т. Ю., Сычев, О. А., Бобров, В. В. (2016). Самоконтроль как ресурс личности: диагностика и связи с успешностью, настойчивостью и благополучием. Культурно-историческая психология, 12(2), 46-58. doi:10.17759/chp.2016120205

Иванова, Т. Ю., Леонтьев, Д. А., Осин, Е. Н., Рассказова, Е. И., Кошелева, Н. В. (2018). Современные проблемы изучения личностных ресурсов в профессиональной деятельности. Организационная психология, 8(1), 85-121.

Иванова, Т. Ю., Леонтьев, Д. А., Рассказова, Е. И. (2016). Функции личностных ресурсов в ситуации экономического кризиса. Психология. Журнал Высшей школы экономики, 13(2), 323-346. . doi:10.17323/1813-8918-2016-2-323-346

Костенко, В. Ю., Леонтьев, Д. А. (2016). Взгляд на себя со стороны: роль рефлексии и самодетерминации в развитии личности. Мир психологии, 3, 97-108.

Левицкая, Т. Е., Богомаз, С. А. (1999). Исследование когнитивных стилей «ригидность-гибкость» и «импульсивность-рефлективность» у школьников. Сибирский психологический журнал, 11, 89-94.

Леонтьев, Д. А. (ред.). (2011). Личностный потенциал: Структура и диагностика. М.: Смысл.

Леонтьев, Д. А. (2016). Саморегуляция, ресурсы и личностный потенциал. Сибирский психологический журнал, 62, 18-37. doi:10.17223/17267080/62/3

Леонтьев, Д. А., Мандрикова, Е. Ю., Осин, Е. Н., Плотникова, А. В., Рассказова, Е. И. (2007). Опыт структурной диагностики личностного потенциала. Психологическал диагностика, 1, 8-31.

Леонтьев, Д. А., Осин, Е. Н. (2014). Рефлексия «хорошая» и «дурная»: от объяснительной модели к дифференциальной диагностике. Психология. Журнал Высшей школь экономики, 11(4), 110-135. 
Люсин, Д. В. (2009). Опросник на эмоциональный интеллект ЭмИн: новые психометрические данные. В кн. Д. В. Люсин, Д. В. Ушаков (ред.), Социальный и эмоциональный интеллект: Om моделей к измерениям (с. 264-278). М.: Изд-во «Институт психологии РАН».

Мандрикова, Е. Ю. (2010). Разработка опросника самоорганизации деятельности. Психологическал диагностика, 2, 87-111.

Перикова, Е. И., Бызова, В. М., Атаманова, И. В., Богомаз, С. А. (2020). Стили реагирования на изменения в структуре психологической системы деятельности молодежи Санкт-Петербурга и Томска. Психологические исследования, 13(70). Режим доступа: http://psystudy.ru

Шадриков, В. Д. (2013). Психология деятельности человека. М.: Изд-во «Институт психологии $\mathrm{PAH} \gg$.

Эльмурзаева, Р. А. (2011). Реализация эмоционального интеллекта в трудовой деятельности. Вестник Томского государственного университета. Экономика, 3, 95-102.

Эсаулова, И. А. (2012). Самоорганизация и саморазвитие как источники инновационной активности персонала. Вестник университета, 1, 192-196.

Ссылки на зарубежные источники см. в разделе References после англоязычного блока.

Перикова Екатерина Игоревна - старший научный сотрудник, лаборатория поведенческой нейродинамики, Санкт-Петербургский государственный университет, кандидат психологических наук.

Сфера научных интересов: психология мышления, метакогнитивная психология, эмоциональный интеллект, психологическая готовность к деятельности, психолингвистика.

Контакты: chikurovaEI@gmail.com

Атаманова Инна Викторовна - доцент, кафедра генетической и клинической психологии, Национальный исследовательский Томский государственный университет, кандидат психологических наук.

Сфера научных интересов: личностно-профессиональное становление в условиях исследовательского университета, кросс-культурное исследование ценностных ориентаций современной молодежи, исследование личностной готовности к деятельности.

Контакты: iatamanova@yandex.ru

Богомаз Сергей Александрович - профессор, кафедра организационной психологии, Национальный исследовательский Томский государственный университет, доктор психологических наук, профессор.

Сфера научных интересов: исследование ценностных ориентаций современной молодежи, специфика личностно-средового взаимодействия в контексте ценностей, психологической системы деятельности и субъективного благополучия.

Контакты: bogomazsa@mail.ru 


\title{
Innovativeness of Personality: A Study of Parameters of Psychological System of Activity in University Youth
}

\author{
E.I. Perikova ${ }^{a}$, I.V. Atamanova ${ }^{b}$, S.A. Bogomaz \\ ${ }^{a}$ Saint Petersburg State University, 7/9 Universitetskaya emb., Saint Petersburg, 199034, Russian \\ Federation \\ ${ }^{b}$ Tomsk State University, 36 Lenin Avenue, Tomsk, 634050, Russian Federation
}

\begin{abstract}
The paper presents the results of the research on the parameters of psychological system of activity in university youth of Saint Petersburg in the context of innovativeness. Studying modern youth's readiness for innovative activity is of considerable interest from the perspective of both their personal and professional development in higher education settings and the involvement of university youth in innovative activity in the leading higher education institutions of the country. The Self-Organization of Activity Questionnaire (Mandrikova, 2010), Differential Test of Reflection (Leontiev, Osin, 2014), EmIn Questionnaire (Lucin, 2009), Change Response Styles Questionnaire (Bazarov, Sycheva, 2012) were used as the research tools in the study. At the first stage the sample consisted of 244 second-year students of Saint Petersburg State University. The article discusses the results of correlation, factor and regression analyses. It was shown that important parameters for developing innovative qualities of modern university youth are the presence of goals, orientation to the present, the ability to systemic reflection and interpersonal emotional intelligence. Fixation on the performance of a task and propensity to planning can have a restraining effect on implementing young people's personal readiness for innovative activity. The implementing style of response to changes is determined by both interpersonal and intrapersonal emotional intelligence as well as characterized by the existence of goals, the persistence in achieving them and orientation to the present. For the first time the study has shown a high significance of emotional intelligence as a parameter of the modern youth's psychological system of activity in the context of developing their innovativeness.
\end{abstract}

Keywords: innovativeness, psychological system of activity, purposefulness, planning, reflection, emotional intelligence, change response styles, university youth.

\section{References}

Artemeva, V. A., Veselova, E. K., Dvoretskaya, M. Y., \& Korjova E. Y. (2018). Social responsibility and personal innovativeness of working and non-working students. Novosibirsk State Pedagogical University Bulletin, 8(5), 73-90. doi:10.15293/2226-3365.1805.05 (in Russian)

Atamanova, I. V., \& Bogomaz, S. A. (2018). Innovativnost' sovremennoi molodezhi i kul'turnye factory sotsial'no-ekonomicheskogo razvitiya [Innovativeness of the modern youth and the cultural factors of the socioeconomic development]. In T. A. Nestik \& Y. V. Kovaleva (Eds.), Sotsial'no-ekonomicheskaya psikhologiya: Sosnoyanie i perspektivy issledovanii [Socioeconomic psychology: Current state and the perspectives of research] (Pt. 1, pp. 281-288). Moscow: Institute of Psychology of the RAS. (in Russian) 
Atamanova, I. V., Bogomaz, S. A., Kozlova, N. V., \& Kashirina, V. I. (2015). An educational technology for developing professionally-oriented EFL communicative competence: Its acmeological potential. Procedia - Social and Behavioral Sciences, 200, 236-242. doi:10.1016/j.sbspro.2015.08.058

Atamanova, I. V., Kozlova, N. V., Bogomaz, S. A., Zalevsky, V. G., \& Neyaskina, Yu. Yu. (2018). Specificity of personality-environment interaction on the example of students from three Russian cities. Tomsk State University Journal of Philosophy, Sociology and Political Science, 41, 90-105. doi:10.17223/1998863X/41/11 (in Russian)

Atamanova, I. V., Starichenko, O. N., \& Bogomaz, S. A. (2013). Psychological features of master and doctoral students at universities oriented towards classical and engineering education. Tomsk State University Journal, 367, 128-135. (in Russian)

Auzan, A. A. (2015). On the possibility of transition to an economic strategy based on the specifics of human capital in Russia. Zhournal Novoi Ekonomicheskoi Associacii, 2(26), 243-248. (in Russian)

Averill, J. R. (2000). Intelligence, emotion, and creativity: From trichotomy to trinity. In R. Bar-On \& D. A. Parker (Eds.), Handbook of emotional intelligence (pp. 363-376). San Francisco, CA: Jossey-Bass.

Baker, S., \& Mehmood, A. (2015). Social innovation and the governance of sustainable places. Local Environment, 20(3), 321-334. doi:10.1080/13549839.2013.842964

Barsh, J., Capozzi, M. M., \& Davidson, J. (2008). Leadership and innovation. McKinsey Quarterly, 1, 37-47.

Baumeister, R. F., Bratslavsky, E., Muraven, M., \& Tice, D. M. (1998). Ego depletion: Is the active self a limited resource? Journal of Personality and Social Psychology, 74(5), 1252-1265. doi:10.1037/0022-3514.74.5.1252

Bazarov T. Y., \& Sycheva M. P. (2012). Development and approbation of Change Response Styles Questionnaire. Psikhologicheskie Issledovaniya, 5(25). http://psystudy.ru (in Russian)

Bogomaz, S. A., \& Karakulova, O. V. (2010). Personal and communicative potential of innovation-oriented and entrepreneurship-oriented individuals. Siberian Journal of Psychology, 37, 48-51. (in Russian)

Bogomaz, S. A., Klochko, V. E., Krasnoryadtseva, O. M., \& Podoynitsina, M. A. (2018). Strategies of self-realization in students. Voprosy Psikhologii, 1, 49-58. (in Russian)

Bogomaz, S. A., Kozlova, N. V., \& Atamanova, I. V. (2015). University students' personal and professional development: The socio-cultural environment effect. Procedia - Social and Behavioral Sciences, 214, 552-558. doi:10.1016/j.sbspro.2015.11.759

Bogomaz, S. A., \& Matsuta, V. V. (2010). Otsenka lichnostnogo potentsiala i vyyavlenie osnovnykh tipov orientatsii na professional'nuyu deyatel'nost' u sovremennoi vyzovskoi molodezhi [The assessment of the personal potential and finding the main types of orientations to professional activity in modern university youth]. Psikhologiya Obucheniya, 12, 77-88. (in Russian)

Bogomaz, S. A., \& Matsuta, V. V. (2014). Tsennostnye orientatsii uchatnikov programmy U.M.N.I.K. i motivatsiya $\mathrm{k}$ innovatsionnoi deyatel'nosti [Value orientations of the participants of U.M.N.I.K. program and their motivation toward innovative activity]. In S. A. Bogomaz \& O. M. Krasnoryadtseva (Eds.), Intellektual'nyi potentsial i innovatsionnaya aktivnost' vuzovskoi molodezhi [Intellectual potential and innovative activity of the university youth] (pp. 100-110). Tomsk: Tomsk State University Publishing House. (in Russian)

Bogomaz, S. A., \& Nepomnashaja, V. A. (2007). To a problem of search of the psychological basis of development of the innovational component of the person in youth and adolescence. Siberian Journal of Psychology, 25, 78-82. (in Russian)

Caruso, D. R., \& Salovey, P. (2004). The emotionally intelligent manager: How to develop and use the four key emotional skills of leadership. San Francisco, CA: Jossey-Bass. 
Elmurzaeva, R. A. (2011). Realization of emotional intelligence in labor activity. Tomsk State University Journal of Economics, 3, 95-102. (in Russian)

Esaulova, I. A. (2012). Samoorganizatsiya i samorazvitie kak istochniki innovatsionnoi aktivnosti personala [Self-organization and self-development as the sources of innovative activity of the staff]. Vestnik Universiteta, 1, 192-196. (in Russian)

Fujisawa, Y., Ishida, Y., Nagatomi, S., \& Iwasaki, K. (2015). A study of social innovation concepts: A Japanese perspective. Japan Social Innovation Journal, 5(1), 1-13. doi:10.12668/jsij.5.1

Gerometta, J., Haussermann, H., \& Longo, G. (2005). Social innovation and civil society in urban governance: Strategies for an inclusive city. Urban Studies, 42(11), 2007-2021. doi:10.1080/00420980500279851

Glor, E. D. (2015). Building theory of organizational innovation, change, fitness and survival. The Innovation Journal: The Public Sector Innovation Journal, 20(2), 1-167. Retrieved from https://www.innovation.cc/books/2015_20_2_4_glor_fit_organizations1a.pdf

Gorchakova, O. Yu., Matsuta, V. V., \& Bogomaz, S. A. (2016). Intellectual and personality factors in the achievement of high exam effectiveness in first-year Russian university students. Psychology in Russia: State of the Art, 9(3), 217-232. doi:10.11621/pir.2016.0315

Gordeeva, T. O., Osin, E. N., Suchkov, D. D., Ivanova, T. Y., Sychev, O. A., \& Bobrov, V. V. (2016). Selfcontrol as a personality resource: assessment and associations with performance, persistence and well-being. Kul'turno-Istoricheskaya Psikhologiya [Cultural-Historical Psychology], 12(2), 46-58. doi:10.17759/chp.2016120205. (in Russian)

Ivanova, T., Leontiev, D., \& Osin, E. (2018). Contemporary issues in the research of personality resources at work. Organizacionnaya Psihologiya [Organizational Psychology], 8(1), 85-121. (in Russian)

Ivanova, T., Leontiev, D., \& Rasskazova, E. (2016). Functions of personality resources in a situation of economic crisis. Psychology. Journal of Higher School of Economics, 13(2), 323-346. doi: 10.17323/1813-8918-2016-2-323-346 (in Russian)

Ivcevic, Z., Brackett, M. A., \& Mayer, J. D. (2007). Emotional intelligence and emotional creativity. Journal of Personality, 75(2), 199-236. doi:10.1111/j.1467-6494.2007.00437.x

Kostenko, V. Y., \& Leontiev, D. A. (2016). Vzglyad na sebya so storony: rol' refleksii i samodeterminatsii v razvitii lichnosti [A view on oneself from the distance: the role of reflection and self-determination in the personal growth]. Mir Psikhologii, 3, 97-108. (in Russian)

Kuehlwein, K. T., \& Rosen, H. (Eds.). (1993). Cognitive therapies in action: Evolving innovative practice. San Francisco, CA: Jossey-Bass.

Leontiev, D. A. (2016). Autoregulation, resources, and personality potential. Siberian Journal of Psychology, 62, 18-37. doi:10.17223/17267080/62/3 (in Russian)

Leontiev, D. A. (Ed.). (2011). Lichnostnyi potensial: Struktura i diagnostika [Personal potential: Structure and diagnostics]. Moscow: Smysl. (in Russian)

Leontiev, D. A., Mandrikova, E. Y., Osin, E. N., Plotnikova, A. V., \& Rasskazova, E. I. (2007). Opyt strukturnoi diagnostiki lichnostnogo potentsiala [The experience of the structural diagnostics of the personal potential]. Psikhologicheskaya Diagnostika, 1, 8-31. (in Russian)

Leontiev, D. A., \& Osin, E. N. (2014). "Good" and "bad" reflection: from an explanatory model to differential assessment. Psychology. Journal of Higher School of Economics, 11(4), 110-135. (in Russian)

Levitskaya, T. E., \& Bogomaz, S. А. (1999). Issledovanie kognitivnykh stilei "rigidnost'-gibkost"” и "impulsivnost'-reflektivnost" u shkol'nikov [The study of cognitive styles "rigidity-flexibility" and "impulsivity-reflexivity" in schoolchildren]. Siberian Journal of Psychology, 11, 89-94. (in Russian) 
Lyusin, D. V. (2009). Oprosnik na emotsional'nyi intellect EmIn: novye psikhometricheskie dannye [The questionnaire on the emotional intelligence EmIn: new psychometric data]. In D. V. Lyusin \& D. V. Ushakov (Eds.), Sotsial'nyi i emotsional'nyi intellekt: Ot modelei $k$ izmereniyam [Social and emotional intelligence: From the models to measurement] (pp. 264-278). Moscow: Institute of Psychology of the RAS. (in Russian)

Mandrikova, E. Y. (2010). Razrabotka oprosnika samoorganizatsii deyatel'nosti [The development of the questionnaire on the self-organization of activity]. Psikhologicheskaya Diagnostika, 2, 87-111. (in Russian)

Mayer, J. D., \& Salovey, P. (2001). Emotional intelligence as a standard intelligence. Emotion, 1(3), 232-242. doi:10.1037/1528-3542.1.3.232

Perikova, E. I., Bysova, V. M., Atamanova, I. V., \& Bogomaz, S. A. (2020). Change response styles in the structure of the psychological system of activity in youth from St. Petersburg and Tomsk. Psikhologicheskie Issledovaniya, 13(70). http://psystudy.ru (in Russian)

Schneider, W. J., Mayer, J. D., \& Newman, D. A. (2016). Integrating hot and cool intelligences: Thinking broadly about broad abilities. Journal of Intelligence, 4(1), 1-25. doi:10.3390/jintelligence 4010001

Shadrikov, V. D. (2013). Psikhologiya deyatel'nosti cheloveka [Psychological activity of a person]. Moscow: Institute of Psychology of the RAS. (in Russian)

Sheldon, K. M., Titova, L., Gordeeva, T. O., Osin, E. N., Lyubomirsky, S., \& Bogomaz, S. (2017). Russians inhibit the expression of happiness to strangers: Testing a display rule model. Journal of Cross-Cultural Psychology, 48(5), 718-733. doi:10.1177/0022022117699883

Sirgy, M. J., Michalos, A. C., Ferris, A. L., Easterlin, R. A., Patrick, D., \& Pavot, W. (2006). The quality of life (QOL) research movement: Past, present and future. Social Indicators Research, 76, 343466. doi:10.1007/s11205-005-2877-8

Stein, S. J., \& Book, H. E. (2011). The EQ edge: Emotional intelligence and your success (3rd ed.). San Francisco, CA: Jossey-Bass.

Ekaterina I. Perikova - Senior Research Fellow, Laboratory of Behavioral Neurodynamics, Saint Petersburg State University, PhD in Psychology.

Research Area: psychology of thinking, metacognitive psychology, emotional intelligence, psychological system of activity, psycholinguistics.

E-mail: chikurovaEI@gmail.com

Inna V. Atamanova - Associate Professor, Department of Genetic and Clinical Psychology, Tomsk State University, PhD in Psychology.

Research Area: personal and professional development in a research university, cross-cultural research of value orientations in modern youth and personal readiness for activity.

E-mail: iatamanova@yandex.ru

Sergey A. Bogomaz - Professor, Department of Organizational Psychology, Tomsk State University, DSc, PhD in Psychology.

Research Area: value orientations of modern youth, specifics of personality-environment interaction in the context of values, psychological system of activity and subjective well-being.

E-mail: bogomazsa@mail.ru 